\title{
Right atrial volume measured by cardiac magnetic resonance correlates with NT-ProBNP and invasive right atrial pressure in pulmonary hypertension, with and without systemic sclerosis
}

\author{
Tom Gyllenhammar ${ }^{1,2^{*}}$, Katarina Steding-Ehrenborg ${ }^{1,3}$, Marcus Carlsson ${ }^{1,2}$, Göran Rådegran ${ }^{4,2}$, Roger Hesselstrand ${ }^{5,2}$, \\ Håkan Arheden ${ }^{1,2}$, Ellen Ostenfeld ${ }^{1,2}$
}

From 19th Annual SCMR Scientific Sessions

Los Angeles, CA, USA. 27-30 January 2016

\section{Background}

Right atrial (RA) pressure (RAP) and NT-ProBNP-levels are important prognostic factors in pulmonary hypertension $(\mathrm{PH})$. The aim of this study was to investigate if RA volume (RAV), emptying fraction and emptying volume measured with cardiac magnetic resonance (CMR) can be used to predict RAP, and to investigate if these measures are related to NT-ProBNP levels. Furthermore, we aimed to determine if RAV in systemic sclerosis patients with precapillary $\mathrm{PH}\left(\mathrm{PH}_{\mathrm{SSc}}\right)$ differs from $\mathrm{PH}$ patients without systemic sclerosis $\left(\mathrm{PH}_{\text {nonSSc }}\right)$.

\section{Methods}

We included 27 patients with $\mathrm{PH}(54 \pm 19$ years, 18 women). $\mathrm{PH}$ was defined as $\mathrm{mPAP} \geq 25 \mathrm{mmHg}$ and PCWP $\leq 15 \mathrm{mmHg}$ at normal or reduced cardiac output. 11 patients with and 16 patients without Systemic Sclerosis and 35 healthy controls (age $31 \pm 9$ years, 16 women) underwent cine CMR to quantify end-systolic maximum $\left(R A V_{\max }\right)$ and end-diastolic minimum $\left(\mathrm{RAV}_{\min }\right)$ right atrial volume indexed to body surface area. Invasive pressures were measured with right heart catheterization and plasma NT-ProBNP level from venous blood samples.

\section{Results}

In all $\mathrm{PH}$ patients $\left(\mathrm{PH}_{\mathrm{SSc}}\right.$ and $\left.\mathrm{PH}_{\text {nonsSc }}\right)$ mRAP was $7 \pm$ $6 \mathrm{mmHg}$, sPAP $73 \pm 23 \mathrm{mmHg}$, mPAP $46 \pm 16 \mathrm{mmHg}$ and PCWP $8 \pm 4 \mathrm{mmHg}$. The correlation coefficient $(\mathrm{r})$ between mRAP and $\mathrm{RAV}_{\min }$ was $0.46(\mathrm{p}=0.015)$ and

'Dept of Clinical Physiology, Cardiac MR Group, Lund, Sweden, Sweden Full list of author information is available at the end of the article between mRAP and $\mathrm{RAV}_{\max } 0.43(\mathrm{p}=0.024)$. Mean NTProBNP was $1894 \pm 2381 \mathrm{ng} / \mathrm{L}$. In the $\mathrm{PH}$ patients, mRAP correlated with NT-ProBNP $(\mathrm{r}=0.5, \mathrm{p}=0.019)$. There was a strong correlation between NT-ProBNP and $\operatorname{RAV}_{\text {min }}(\mathrm{r}=0.7, \mathrm{p}=0.0003)$ and $\operatorname{RAV}_{\max }(\mathrm{r}=0.67$, $\mathrm{p}=0.0006)$.

$\mathrm{RAV}_{\text {min }}$ in patients with $\mathrm{PH}_{\text {nonssc }}\left(97 \pm 35 \mathrm{ml} / \mathrm{m}^{2}\right)$ was higher as compared to $\mathrm{PH}_{\mathrm{SSc}}\left(54 \pm 23 \mathrm{ml} / \mathrm{m}^{2}, \mathrm{p}<0.05\right)$ and healthy controls $\left(57 \pm 12 \mathrm{ml} / \mathrm{m}^{2}, \mathrm{p}<0.05\right)$, but did not differ between patients with $\mathrm{PH}_{\mathrm{SSc}}$ and healthy controls (NS). There was also a significant difference in RAVmax between the patients with $\mathrm{PH}_{\text {nonssc }}\left(69 \pm 32 \mathrm{ml} / \mathrm{m}^{2}\right)$ and $\mathrm{PH}_{\mathrm{SSc}}\left(32 \pm 19 \mathrm{ml} / \mathrm{m}^{2}, \mathrm{p}<0.05\right)$ as well as healthy controls $\left(24 \pm 8 \mathrm{ml} / \mathrm{m}^{2}, \mathrm{p}<0.05\right)$, yet no difference between $\mathrm{PH}_{\mathrm{SSc}}$ and healthy controls (NS). RA emptying fraction differed between the $\mathrm{PH}_{\text {nonssc }}$ patients and the healthy controls $(31 \pm 12 \%$ vs. $54 \pm 15 \%$, p < 0.05$)$, but neither between $\mathrm{PH}_{\mathrm{SSc}}$ patients $(43 \pm 18 \%)$ and healthy controls nor PH patients (ns). There was no significant difference in RA emptying volume between the groups $\mathrm{PH}_{\text {nonSSc }}(29 \pm 13 \mathrm{ml} / \mathrm{m} 2), \mathrm{PH}_{\mathrm{SSc}}\left(21 \pm 11 \mathrm{ml} / \mathrm{m}^{2}\right)$ and the healthy controls $\left(31 \pm 10 \mathrm{ml} / \mathrm{m}^{2}\right)$.

\section{Conclusions}

This study shows that non-invasive measures of right atrial volumes by cardiac magnetic resonance correlates with NT-ProBNP and invasive right atrial pressure in patients with precapillary $\mathrm{PH}$. Furthermore, $\mathrm{RAV}_{\text {min }}$ and $\mathrm{RAV}_{\max }$ were increased in $\mathrm{PH}_{\text {nonSSc }}$ compared to $\mathrm{PH}_{\text {SSc }}$. Future studies are needed to investigate the clinical advantages of these complementary measures in the diagnostics of pulmonary hypertension. 

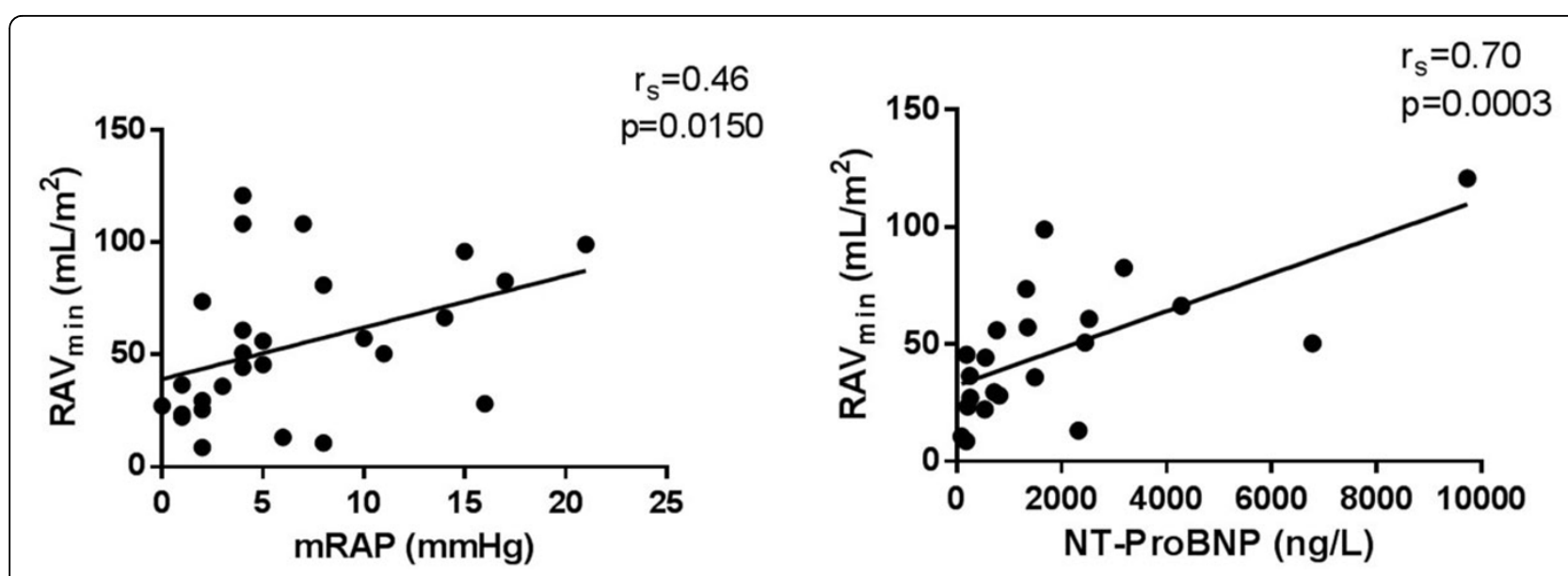

Figure 1 The left panel shows the minimum right atrial volume $\left(\mathrm{RAV}_{\min }\right)$ compared to invasive mean right atrial pressure (mRAP), the right panel shows the $\mathrm{RAV}_{\min }$ compared to NT-ProBNP.

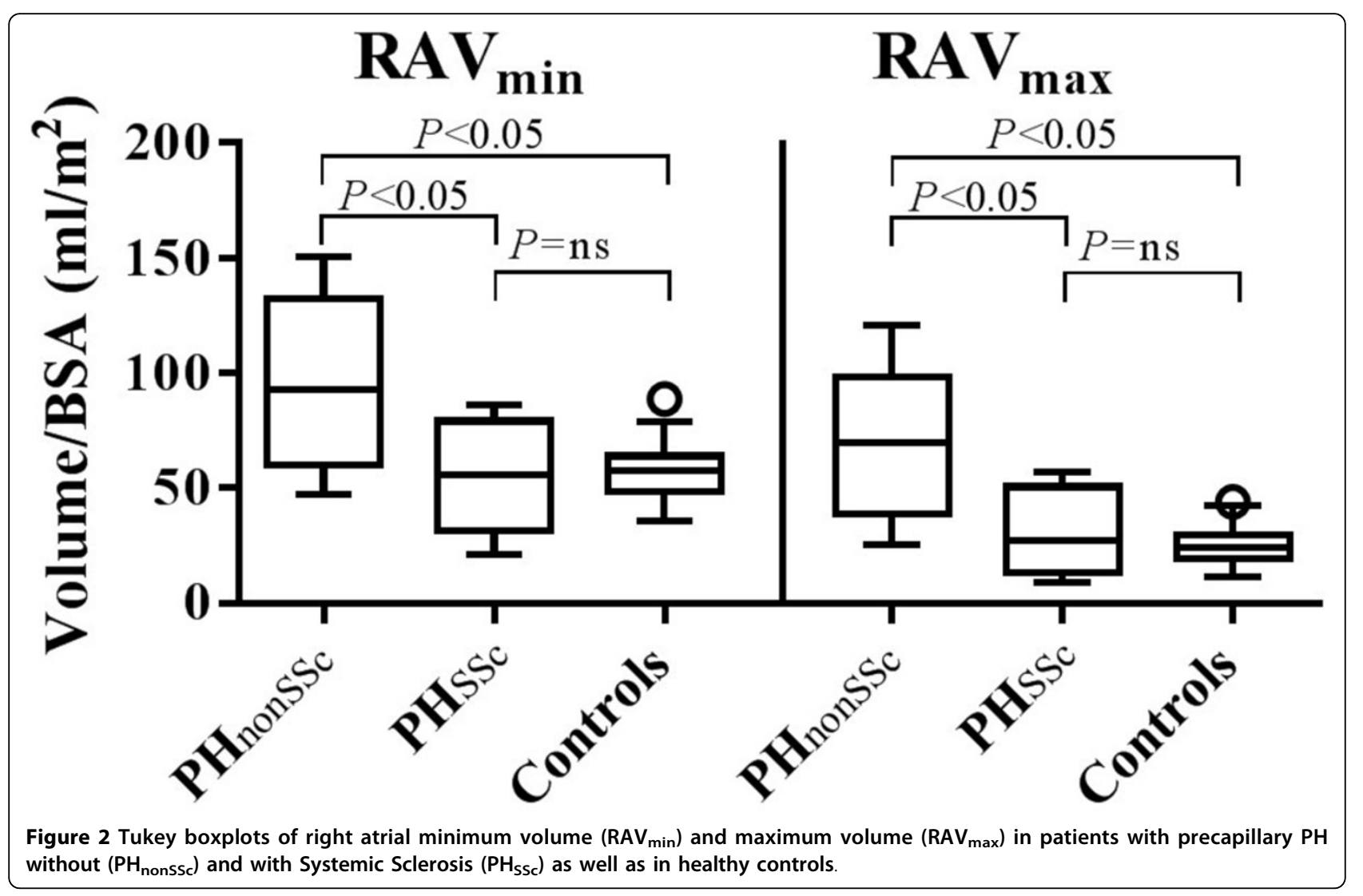

Authors' details

'Dept of Clinical Physiology, Cardiac MR Group, Lund, Sweden, Sweden. ${ }^{2}$ Lund University, and Lund University Hospital, Department of Clinical Sciences Lund, Lund, Sweden. ${ }^{3}$ Department of Health Sciences, Lund University, Physiotherapy, Lund, Sweden. ${ }^{4}$ The Section for Heart Failure and Valvular Disease, Lund, Sweden. ${ }^{5}$ Department of Rheumatology, Lund, Sweden.

Published: 27 January 2016
doi:10.1186/1532-429X-18-S1-P300

Cite this article as: Gyllenhammar et al:: Right atrial volume measured by cardiac magnetic resonance correlates with NT-ProBNP and invasive right atrial pressure in pulmonary hypertension, with and without systemic sclerosis. Journal of Cardiovascular Magnetic Resonance 201618 (Suppl 1):P300. 